\title{
EFFECTS OF PULP PREPARATION AND PAPERMAKING PROCESSES ON THE PROPERTIES OF OCC FIBERS
}

\author{
Jinquan Wan, ${ }^{\mathrm{a}, \mathrm{b}}$ Jing Yang, ${ }^{\mathrm{b}, \mathrm{c}, *}$ Yongwen Ma, ${ }^{\mathrm{a}, \mathrm{b}}$ and Yan Wang ${ }^{\mathrm{b}}$ \\ Changes of the pore structure of recycled fibers and the strength \\ properties of papers produced by old corrugated container (OCC) \\ recycled fibers were studied, after they were subjected to different stock \\ preparation and papermaking processes. In this paper, the effects of \\ beating, sizing, pressing, and drying on fiber properties were \\ investigated, and the porous structure of fibers was analyzed by nitrogen \\ adsorption technique. The results showed that beating, pressing, and \\ other physical processes significantly influenced the fiber properties, \\ whereas the effects of sizing were minor. Significant changes of water \\ retention value (WRV), crystallinity index, and paper strength were \\ observed after those processes. Further, an effort has been made to \\ show relationships between pore structure and macroscopic properties \\ (WRV, crystallinity index) of recycled fibers.
}

Keywords: Recycled fibers; Pore structure; Crystallinity index; Tensile index

Contact information: a: School of Environmental Science and Engineering, South China University of Technology, Guangzhou 510006, PR China; b: State Key Laboratory of Pulping and Papermaking Engineering, South China University of Technology, Guangzhou 510640, PR China; c: School of Light Chemical and Food Science Engineering, South China University of Technology, Guangzhou 510640

*Corresponding author: yangjing455@126.com

\section{INTRODUCTION}

With the prosperous development of China's paper industry, recycled fiber has become an extremely important raw material. Full utilization of recycled fibers in the paper industry not only can ease the shortage of plant fiber resources, but also save the energy consumption, as well as effectively reduce the pollution load caused by papermaking processes. According to the statistics of the China Paper Association, the total consumption of recycled fibers in the papermaking industry was 44.39 million tons in 2008 in China, and increased to 49.39 million tons in 2009 , accounting for $62 \%$ of the total fiber raw materials. It is obvious that the share of recycled fibers in total raw fiber resources will continue a steadily rising trend (China Paper Association 2010). In addition, corrugated container, as an environmental friendly packaging material, is one of the main sources of recycled fibers, with a high degree of recycling for many years, accounting for approximately $40 \%$ of the total wastepaper (Guo et al. 2011). OCC is mainly composed of used unbleached kraft pulp, bleached kraft pulp, hardwood semichemical pulp, and grass pulp. The major problem with recycling of old corrugated container is the loss of its strength properties (Nazhad and Sodtivarakul 2004). Some researchers have investigated the OCC pulp properties after recycling; generally speaking, the OCC pulp characteristics in terms of fibers surface properties and strength properties 
of paper sheets tended to decreased with the increase of recycling times ( $\mathrm{Li}$ et al. 2010; Wu et al. 2010; Seo 2002; Bajpai, 2010)

These various different changes in fiber morphology and surface characteristics are generally undesirable, since the changes tend to impede growth prospects for the use of recycled fibers in papermaking. As always, the main reason accounting for the inferior properties of recycled fibers is the hornification, i.e. the irreversible loss in swelling capacity of the fiber wall resulting from a drying and rewetting cycle (Jayme 1944). The mechanism responsible for hornification has been the subject of a long debate, and many classic theories have been developed to explain it. For instance, Thode et al. (1955) reported that the hornification is caused by the irreversible closing-up of micropores and cracks during drying. Stone and Scallan (1965 and 1968) carried out comprehensive studies on the effect of drying on the structure of the cell wall. It was observed that large and intermediate size pores were reduced for drying. This concept was also discussed by Jayme and Hunger (1958). Other researchers proposed the auto-crosslinking hypothesis can be as a source of fiber hornification during recycling (Back and Klinga 1963; Back et al. 1967). Reorganization and co-crystallization of cellulose chains during drying, as another source of hornification, was discussed by other researchers (Ehmrooth 1978; Ingram et al. 1974; Kulshreshtha et al. 1973; Morosoff 1974). However, the mechanism for hornification has still not been completely understood. To understand the changes occurring in stock preparation and papermaking procedures are important for overcoming the inferior properties of recycled fibers.

A significant amount of research and development efforts has been ultimately attempted to overcome the loss of paper strength made from recycled fibers (Lvov et al. 2006; Lofton et al. 2005; Laine et al. 2000, 2002, 2003; Ekevåg et al. 2004). Physical, chemical and biological treatment can be applied for fiber modification, such as beating, carboxymethyl treatment using the chloroacetic acid, adding cellulose derivatives, enzyme treatment (Blomstedt et al. 2007; Choi and Jong, 2001; Jiao et al. 1998; Pala et al. 2001; Rácz and Borsa 1997; Waterhouse and Liang 1995), etc.

As is well known, papermaking processes significantly affect fiber properties (Hubbe et al. 2003; Hubbe et al. 2007; Lyne and Gallay 1950; Khantayanuwong 2002a; Vainio and Paulapuro 2007). Previous researches on the subject have mainly focused on the changes of fiber properties as a result of single or two-step processes such as beating, pressing, and drying, etc. Indicators such as water retention value (WRV) and handsheet strength have been used to characterize the fiber properties. By contrast, in our research the effects of papermaking processes involved beating, sizing, pressing, and drying on fiber properties and the changes of porous structure within the fiber wall were studied together. The porous structure of fibers plays a critical role in papermaking (Andreasson et al. 2003; Maloney and Paulapuro 1999). Moreover, pore size distribution is an important attribute of porous structure in fiber wall, and changes of pore size and pore volume are also crucial to the ability of molecules to diffuse in and out of the fiber wall (Andreasson et al. 2003). Therefore, analyzing pore size distribution of pores within the fiber wall is justifiable to investigate the effects of different treatments on fiber porous structure. In our study, we aimed to gain a deep understanding of the mechanism of fiber properties degradation from the standpoint of pore structure, and clarify the relationships among paper sheet strength, WRV, crystallinity of cellulose, and fiber pore structure. 


\section{EXPERIMENTAL}

The experiment consisted of two parts. The former part involved analysis of the porous structure of fiber wall by changing the conditions of beating, pressing, and drying. The latter part was used to compare the effects of papermaking processes on fiber properties, including WRV, crystallinity, and strength properties of handsheets.

\section{Materials and Sample Preparation}

OCC was torn into pieces of about $25 \times 25 \mathrm{~mm}$ and soaked in water for $24 \mathrm{~h}$ at room temperature, then slurried with a slusher (N-197VT, Adirondack Machine Corporation, USA) at a consistency of $5 \%$ and temperature of $50{ }^{\circ} \mathrm{C}$ for $10 \mathrm{~min}$. The fiber has an average length of $0.53 \mathrm{~mm}$ and an average width of $16.91 \mu \mathrm{m}$, fines content of $33.13 \%$, measured by Fiber Quality Analyzer (FQA) (KajaaniFS300, Metso Automation, Finland).

The prepared samples were beaten in a PFI refiner according to the TAPPI T248 sp-2000 standard, to obtain pulps with different beating levels determined by Beating Degree Tester according to the GB/T3332-2004 standard. From beaten pulp, a fiber suspension with fiber consistency of $1.2 \%$ was prepared, and $0.3 \%$ of AKD (based on dry weight of pulp) was added to the pulp suspensions with continuous stirring at 6,000 revolutions. Then the mixture was subjected to the preparation of handsheets with a basis weight of $120 \mathrm{~g} / \mathrm{m}^{2}$ on a handsheet machine (RK3-KWTjul, Vorchdorf, Austria) with the Rapid Köthen method according to the GB/T 24214-2009 standard. Pressing was conducted on a squeezer (400-1, Labtech Company, USA) with the pressure and pressing time controlled independently, firstly, the pressure level varied from 0.1 to $0.5 \mathrm{MPa}$ and pressing time level was fixed at $5 \mathrm{~min}$; then the pressing time varied from 5 to $25 \mathrm{~min}$ with pressure at $0.45 \mathrm{MPa}$. The effects of pressure and pressing time on pulp fibers were studied respectively. Then the sheets were dried on a Formax 12'Drum Dryer (ThwingAlbert Instrument Company, USA). Drying temperature and duration were 80 and $120{ }^{\circ} \mathrm{C}$ for $15 \mathrm{~min}, 100{ }^{\circ} \mathrm{C}$ for 10,15 , and $20 \mathrm{~min}$.

\section{Determination of Pore Structure}

Many different methods can be used to characterize the porous structure of the fiber wall. The most frequently used method is the Solute Exclusion Technique (SET) (Böttger et al. 1983; Stone and Scallan 1968). Other techniques, such as Inverse Size Exclusion Chromatography (ISEC) (Aggerbrandt and Samuelsson 1964; Berthold and Salmén 1997) and the Nuclear Magnetic Resonance (NMR) relaxation method (Li, et al. 1993; Li and Eriksson 1994; Maloney et al. 1997) are also available.

In this study, nitrogen adsorption measurements were used to reveal details of the porous structure of the cell wall of pulp fibers (Mancosky et al. 2004; Sawabe and Kitagawa 1978; Stone and Scallan 1965; Yu et al. 2009). The technique requires samples in dry state, because drying pulps from polar liquid such as water causes collapse of pores and a loss of internal surface (Wang et al. 2006). Thus prior to analysis, the aqueous medium suspending the fiber samples was replaced with acetone, followed by freezedrying in freeze-drier (Modulyod-230, Thermo Company, USA). The measurement was carried out with an ASAP 2020 volumetric adsorption analyser (Micromeritics Co., USA). 
$\mathrm{N}_{2}$ was used as adsorbate, and adsorption-desorption of high-purity $\mathrm{N}_{2}$ was determined at $77.5 \mathrm{~K}$ with a liquid nitrogen trap using astatic volumetric method. The pore size distribution was obtained using the Barrett-Joyner-Halenda algorithm (Barrett et al. 1951; Persson et al. 2004), the isotherm was characterzed as type IV. the Table 1 .

In the second part, the OCC fiber samples were exposed to treatments as shown in

Table 1. Samples Prepared

\begin{tabular}{ccccc}
\hline Sample code & Beating & Sizing & Pressing & Drying \\
& $34{ }^{\circ} \mathrm{SR}$ & $0.3 \%$ AKD & $0.3 \mathrm{Mpa}, 10 \mathrm{~min}$ & $100{ }^{\circ} \mathrm{C}, 15 \mathrm{~min}$ \\
\hline $\mathrm{a}$ & + & + & + & + \\
$\mathrm{b}$ & - & + & + & + \\
$\mathrm{c}$ & + & - & + & + \\
$\mathrm{d}$ & + & + & + & air dried \\
$\mathrm{e}$ & + & + & + & + \\
\hline
\end{tabular}

+ stands for sample was subjected to the process, - means not.

The paper sheets were conditioned in a controlled environment (temperature of $23 \pm 1{ }^{\circ} \mathrm{C}$ and relative humidity of $50 \pm 1 \%$ ) before measurement of sizing degree and strength properties. The sizing degree was determined by testing the water absorption with the Cobb method according to the GB/T 1540-2002 standard. The test was performed with 60 seconds of exposure, and the Cobb value was tested to $28 \mathrm{~g} / \mathrm{m}^{2}$. Tensile strength of handsheets was measured by a tensile machine (CE062, Lorentzen Wetter Company, Sweden) according to the GB/T 12914-2008 standard.

\section{Determination of WRV}

The water retention value (WRV) is an important property closely associated with fiber cellulose crystallinity and swelling capability (Forsström et al. 2005; Gumuskaya et al. 2003). The measurement of WRV was conducted using the centrifugal method with $1.5 \mathrm{~g}$ samples (o.d.) at $3000 \mathrm{~g}$ for $15 \mathrm{~min}$ according to ISO 23714-2007. After centrifugation, the fiber mat was weighed in a pre-weighed weighting bottle, subsequently dried in a drying oven at $105 \pm 2{ }^{\circ} \mathrm{C}$ for $24 \mathrm{~h}$, and then re-weighed. WRV was calculated with the following equation,

$$
W R V=\frac{m_{1}-m_{2}}{m_{2}} \times 100 \%
$$

where $m_{1}$ is the weight of the wet pulp after centrifugation and $m_{2}$ is the weight of the dry pulp (in grams). 


\section{Determination of the Infrared Crystallinity Index}

Crystallinity index was determined by infrared spectroscopy, which was carried out with a Fourier Transform Infrared (FTIR) instrument (Nexus 670, Thermo Nicolet Company, USA). During sample preparation, the freeze-dried samples were reduced to small pieces prior to mixing with potassium bromide and transformed into pellets for analysis. Crystallinity index was calculated from the relative intensities of the infrared bands, finding the ratios of $1372 / 2900 \mathrm{~cm}^{-1}$ (Nelson and O'Connor 1964),

$$
\text { N.O'KI }=\frac{I_{1372}}{I_{2900}} \times 100 \%
$$

where $I_{1372}$ represents the intensity $\left(1372 \mathrm{~cm}^{-1}\right)$ of the band belonging to the $\mathrm{CH}$ bending vibration and $I_{2900}$ is the intensity $\left(2900 \mathrm{~cm}^{-1}\right)$ of the band belonging to the $\mathrm{CH}$ and $\mathrm{CH}_{2}$ bending vibrations.

All experiments were run in triplicate, and the relative standard deviation (RSD) was used to express the errors of analysis. Each pulp sample was tested six times to obtain an average value.

\section{RESULTS AND DISCUSSION}

\section{Effects of Different Treatments on Recycled Fiber Porous Structure} Effects of beating on porous structure of fiber wall

Dubinin (Gregg et al. 1982) divided the pores of porous solids into three groups: micropore (radius $<20 \AA$ ), mesopore (radius: 20 to $500 \AA$ ), and macropore (radius $>500$ $\AA$ ). In our paper we apply these standard terms to classify the pores in fibers observed from the pore size distribution detector.

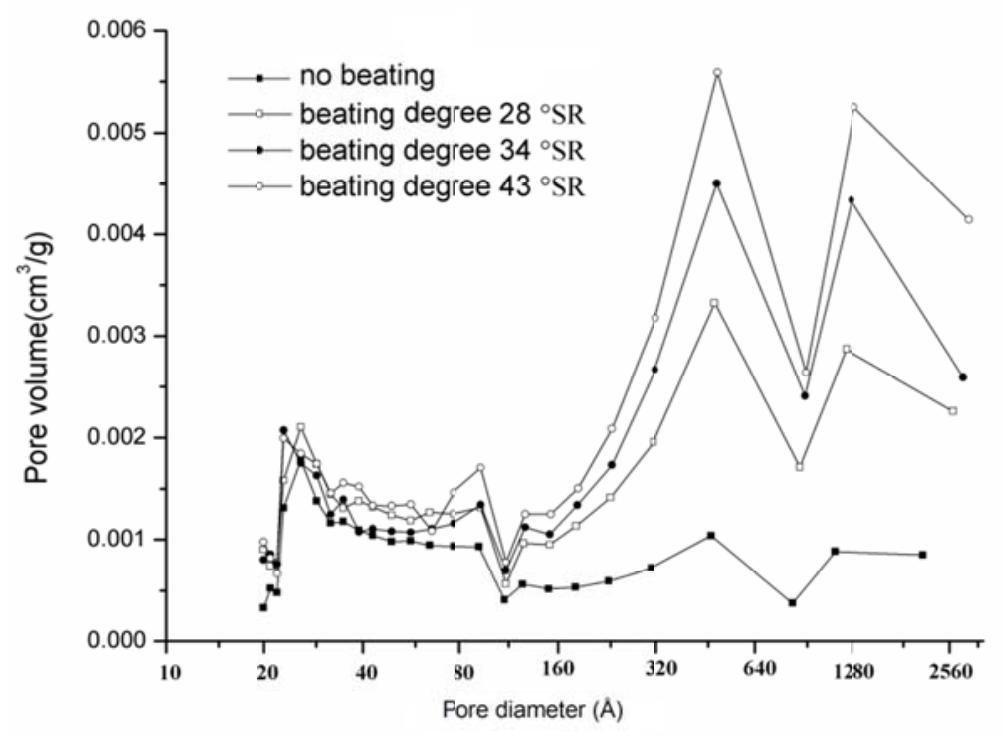

Fig. 1. Pore size distribution of OCC fibers at different beating levels 
Figure 1 presents the pore size distribution of OCC fibers treated with various beating levels. Mesopores made up the majority of cell wall pore volume. The pores of cell walls were expanded to different extents by beating, and the pores size and volume increased with the development of beating levels. Two remarkable peaks can be observed at around pore diameter of 472 and $1127 \AA$ for pulp fibers, which was attributed to the significant contributions of pores (at 472 and $1127 \AA$ ) to the pore volumes, indicating this kind of pores made up the great part of cell walls of fibers. Meanwhile, the changes of pores with pore diameter at 472 and $1127 \AA$ were more pronounced than other pores.

Changes in pore characteristics of cell wall, such as specific surface area and volume, size, are associated with the extent of fibrillation at fiber surfaces due to the physical contributions of beating. In the early stage of beating, the primary and outer secondary walls of the fiber were disrupted and in part removed, i.e., external fibrillation (Emerton 1957). Subsequently, the refining process tended to open up submicroscopic spaces within the lamellar structure of cell walls, and created further internal delamination of fibers. Thus it was likely to contribute to the increase of pore size and pore volume. The pores with diameter greater than 120 showed more changes in comparison to those with diameter less than 120, indicating that beating significantly influenced the large-scale pores. This is in consistent with the previous report (Wang et al. 2006).

\section{Effects of Pressing on Porous Structure of Fiber Wall}

Various authors have observed that the swelling capability of fibers tended to decrease when subjected to wet-pressing conditions (Robertson 1964; Carlsson and Lindström 1984). Maloney et al. (1997) conducted the NMR analysis and found that pressing had a disproportionate effect in closure of the larger pores that were present in fibers. In the study, the effects of pressure and pressing time on pore structure of fibers were studied independently. Figures 2 and 3 present the pore size distributions for OCC fibers subjected to different pressing conditions.

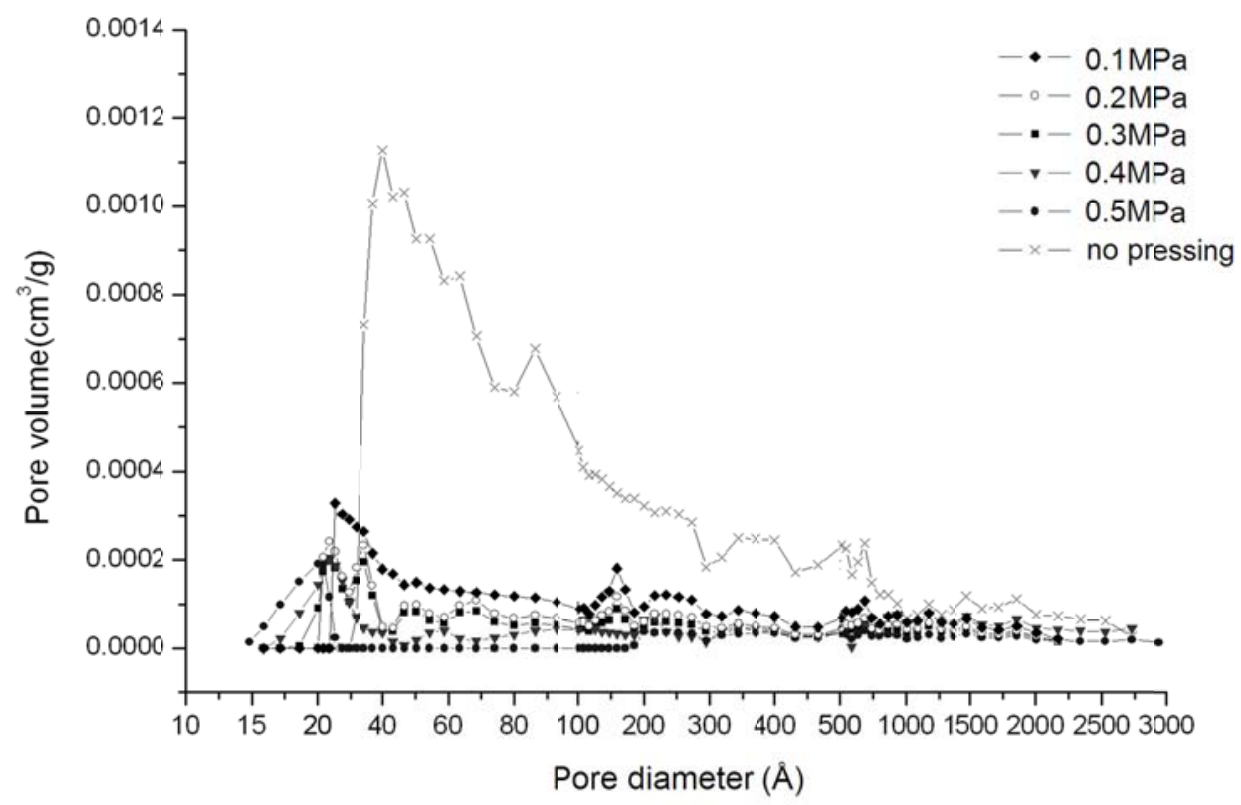

Fig. 2. Pore size distribution of OCC fibers under different pressures (pressed for $10 \mathrm{~min}$ ) 


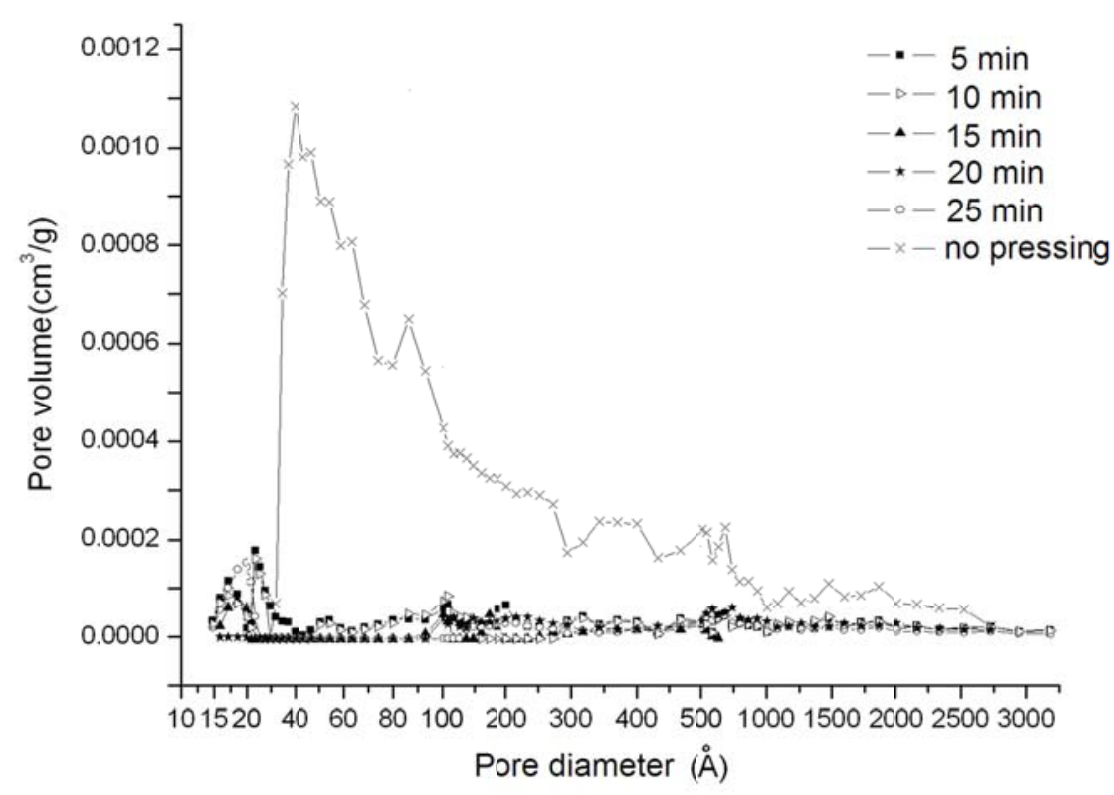

Fig. 3. Pore size distribution of OCC fibers at different pressing time (0.45 MPa)

As shown in Figs. 2 and 3, distinct differences in pore size distributions were observed for pressed and unpressed fibers. The pore volumes in cellulose fibers decreased significantly with the increase of pressing pressure and time. It is a welldocumented phenomenon that pressing results in pore closure in cellulose fibers. This is because cellulose fibres shrink due to the removal of pore water by applying a pressure pulse (Bežanović and Van Duijn 2007). The moisture content in fibers is crucial for pore structure of cell wall. Various researchers have conducted similar investigations, concluding that the differences in water contents of fiber substantially influenced the pore characteristics of cellulose fibers (Häggkvist et al. 1998). For instance, Stone and Scallan (1966) observed significant decreases in the surface areas of sulfite pulp in cases where the water content was reduced to $42 \%$ or below.

As can be seen from Figs. 2 and 3, no distinct differences in pore size distributions were observed for the pulp fibers pressed $5 \mathrm{~min}$ and other time levels (or pressed at different pressures, as in Fig. 2), demonstrating that the pores closed severely and irreversibly once the pulp fibers were exposed to pressing treatments, regardless of the severity of pressing conditions. Moreover, the most significant changes among the pores in fibers were associated with the mesopores, showing the effect of pressing was mainly affecting the mesopores.

\section{Effects of Drying on Porous Structure of Fiber Wall}

As shown in Figs. 4 and 5, the changes of OCC fibers exposed to restrictive drying were evaluated. First, we fixed the drying time at $15 \mathrm{~min}$, varying the drying temperature as 80,100 , and $120{ }^{\circ} \mathrm{C}$. Then the temperature was fixed at $100{ }^{\circ} \mathrm{C}$, while varying the time as 10,15 , and $20 \mathrm{~min}$. 


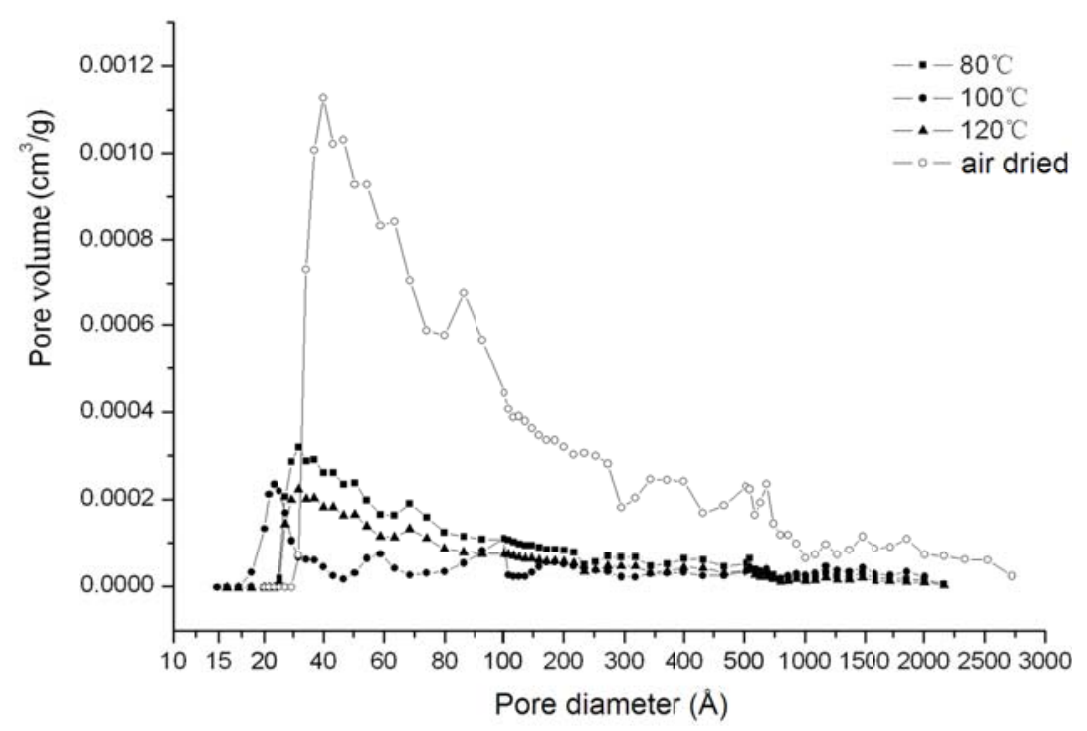

Fig. 4. Pore size distribution of OCC fibers at different drying temperatures (15min)

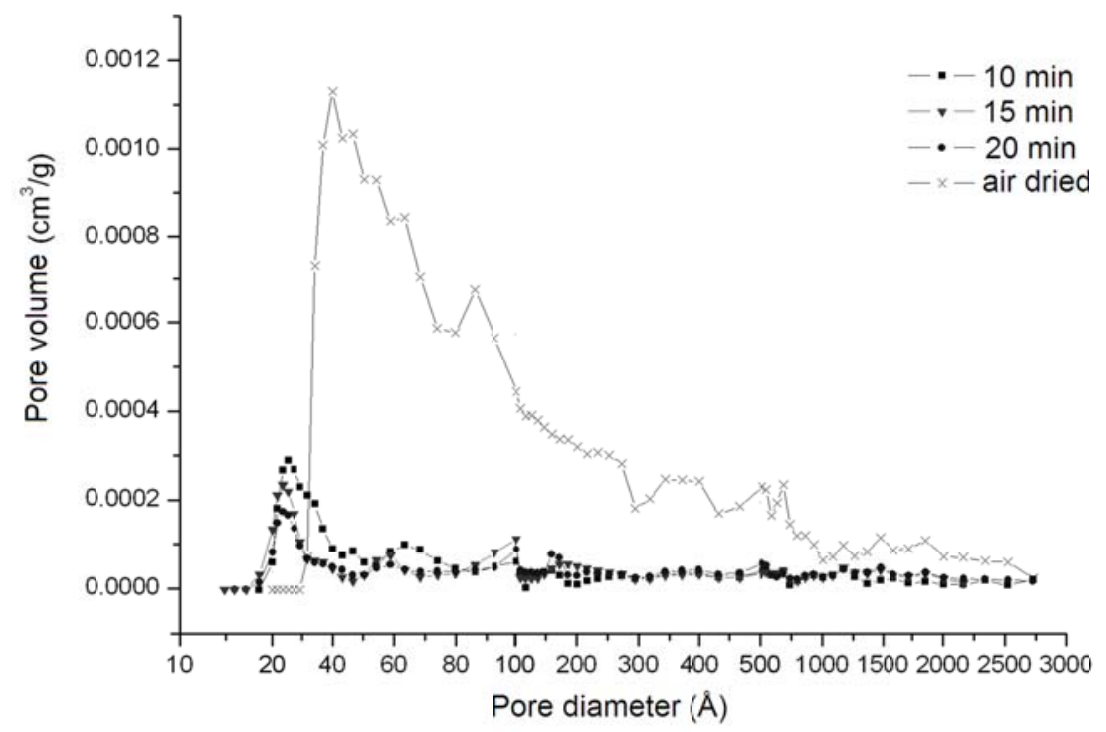

Fig. 5. Pore size distribution of OCC fibers at different drying time $\left(100{ }^{\circ} \mathrm{C}\right)$

As indicated in Figs. 4 and 5, the drying procedure significantly influenced the pore characteristic of fibers. Compared with air dried fibers, considerable losses in pore volume were observed for dried fibers, and when pulp fibers were subjected to unrestrained drying, the pore in cell wall of fibers shifted to small-scale pores, demonstrating the phenomenon of pore closure in fibers during drying process. The subject on mechanism for pore closure in fibers during drying has been investigated by many researchers (Sheikhi et al. 2010; Häggkvist et al. 1998); however, it has not been completely understood. One possible mechanism views that when water evaporates from the pore, high surface tension of water pulls the cell wall together and the pore size becomes smaller or pores suffer from closure (Park et al. 2006). 


\section{Effects of Different Treatments of Recycled Fibers on Crystallinity Index}

The following figures show that the recycled fiber properties (WRV, crystallinity index of fiber, and tensile index of paper sheet) changed in response to beating, sizing, pressing, and drying, illustrating the effects of different treatments on these properties of recycled fibers. Samples subjected to treatments are listed in Table 1.

The crystallinity index obtained from FTIR spectrum of fibers subjected to different treatments and the effects of papermaking processes on crystallinity index are showed in Fig. 6. As shown, the increases in crystallinity index were observed during pressing and drying processes, and the increase of crystallinity index during drying was higher than pressing (around 15\%). The explanations are related to the increase of hydrogen bonding between cellulose molecules during pressing, and the re-organization of cellulose chains and the transformation of amorphous regions to crystalline regions in cellulose during drying (Karnis 1994). Nevertheless, the crystallinity index was decreased by $6.76 \%$ after beating, which is slighting different from the results obtained by Ioelovich (2010). He noted that the crystallinity of bleached sulfate softwood cellulose fibers was increased by approximately $3.1 \%$, which is probably because the fiber materials and measurement method were different between the two studies. However, no significant effect on crystallinity due to the sizing process was observed.

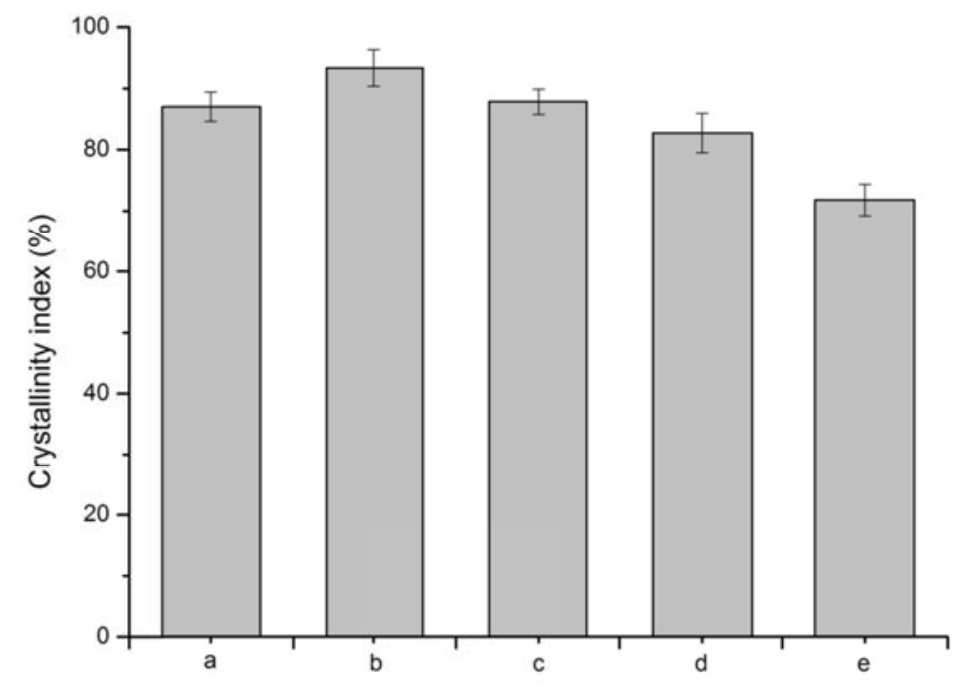

Fig. 6. Changes of crystallinity index with different treatments

(A pair of bars denotes a rage of $95 \%$ confidence level, a: all treatments,b:no beating;c:no sizing,d:no pressing,e:no drying)

\section{Effects of Different Treatments of Recycled Fibers on WRV}

Figure 7 illustrates the effects of different treatments (beating, sizing, pressing and drying) on WRV. The beating operation had the most significant effects on swelling capability, compared to other processes, and the WRV was considerately enhanced by $24.7 \%$ after beating. This is attributed to the delamination behavior, an important feature induced by beating (Chevalier-Billosta et al. 2007). The delamination of cell wall created large pores, which improved the water-carrying capacity of the fiber. At the same time, fiber swelling was accompanied by an increase in fiber flexibility and fibrillation in the 
beating process (Sheikhi et al. 2010), and as a result the WRV increased. No significant changes in WRV were found for the sizing process. However, the swelling capability of fibers deteriorated to some extent during the pressing and drying processes, for which the losses of WRV were $4.75 \%$ and $8.57 \%$, respectively. The explanations may be related to a collapse of the pores upon pressing and drying, which reduced the water-carrying capacity of the fiber (Brancato et al. 2007).

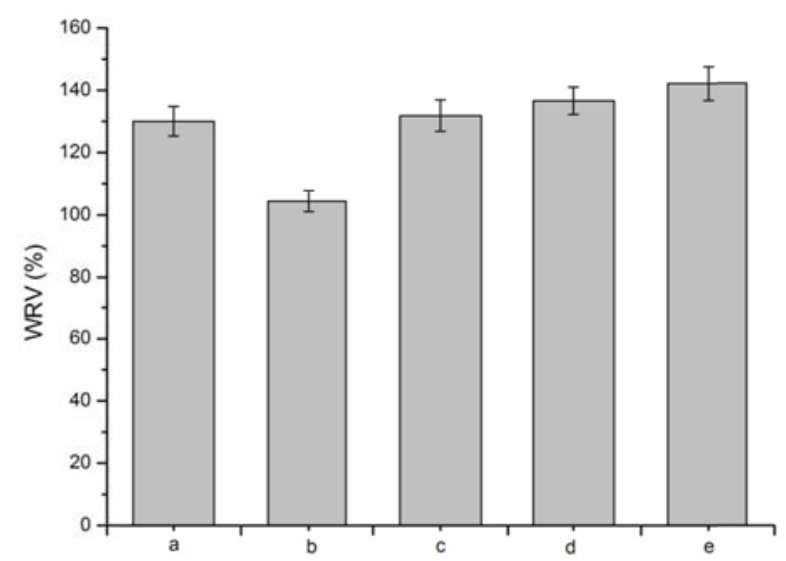

Fig. 7. Changes of WRV with different treatments

(Limit bars denotes a range of $95 \%$ confidence level,

a: all treatments, b: no beating; c: no sizing, d: no pressing, e: no drying)

\section{Effects of Different Treatments of Recycled Fibers on Paper Sheet Strength}

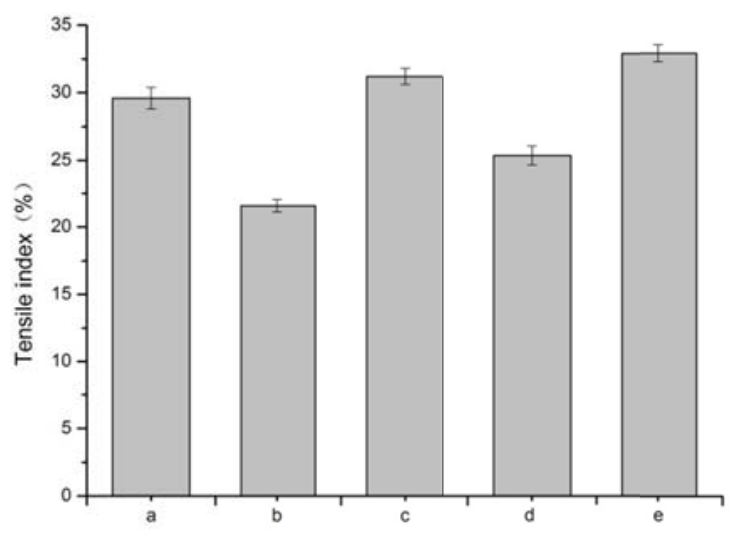

Fig. 8. Changes of tensile index with different treatments (Limit of bars denotes a range of $95 \%$ confidence level, a: all treatments, b: no beating; c: no sizing, d: no pressing, e: no drying)

As shown in Fig. 8, sizing had less influence on tensile index of paper sheets compared with other processes. The tensile index of handsheets was decreased by $5.13 \%$ after sizing in comparison with sample $\mathrm{c}$ and a. Nevertheless, the strength property of paper was greatly increased by beating and pressing, compared with unbeaten and unpressed samples, the increase of tensile index were $37.2 \%$ and $16.7 \%$, respectively. The explanation for this increase may be related to internal fibrillation and reinforced 
hydrogen bonding between fibers during beating process (Wang et al. 2003). In relationship to the pressing process, it densified the sheet structure, resulting in the increase of bonded area and numbers of bonds, which was favourable for improving inter-fiber bonding (Vainio and Paulapuro 2007); consequently the tensile strength of paper sheet was developed. However, tensile index of handsheet was decreased by $10 \%$ after drying, which may be due to the collapse of pores and loss in fiber swelling capability, the characteristics of hornification upon drying (Nazhad 1994).

\section{The Relationships among the WRV, Crystallinity, and Pore Structure of Fiber Wall}

It is well known that pore structure within cell wall, swelling capability and cellulose crystallinity, are important for the strength of paper made from the fibers (Andreasson et al. 2003; Sheikhi et al. 2010; Hubbe et al. 2007; Chevalier-Billosta et al. 2007; Nanzhad 1994). The opened pore structure is favorable for the absorption of water molecules to fibers (Stana-Kleinschek et al. 2001), which will result in the increase of fiber swelling and flexibility. Meanwhile, fiber flexibility and swellability are the main contributors to the strength of interfiber bonding (Sheikhi et al. 2010). On the other hand, in the structure of cellulose, the crystalline regions are interrupted every $60 \mathrm{~nm}$ with noncrystalline amorphous regions for all raw materials (Sheikhi et al. 2010). Therefore, the crystalline structure of cellulose substantially affects the physical and mechanical properties of cellulose fibers. In addition, the fiber swellability is closely associated with crystalline structure of cellulose (Kongdee et al. 2004; Khantayanuwong et al. 2002b). The water does not penetrate into crystalline domains of cellulose (Salmen 1988); thus the increase in crystallinity of fibers will reduce the water up-take by the cell wall, as a result the swelling ability of fibers will be restricted (Nazhad 1994). In other words, the flexibility of fiber is inversely related to the cellulose crystallinity.

\section{CONCLUSIONS}

Changes of pore structure in fibers under different conditions and effects of recycling processes (beating, sizing, pressing, and drying) on WRV and crystallinity of OCC pulp fibers, as well as the tensile strength of paper sheet made from the recycled fibers were studied. Relationships of pore characteristics of cell wall within fibers, WRV, and crystallinity of cellulose were also evaluated.

The above-mentioned papermaking processes affected the porous structure of cell wall within fiber. At the beating level at $34{ }^{\circ} \mathrm{SR}$, the fiber swelling capability was substantially developed, resulting from the expanded pores produced in beating, while the crystallinity of cellulose was slightly decreased. Compared with other processes, sizing had less impact on fiber properties. Both pressing and drying processes considerately influenced the fiber properties, with greater changes occurring especially in the drying process. The fiber lumens were collapsed and pores closed irreversibly, inducing the loss of swelling capability. Meanwhile, the transformation of amorphous region to crystalline form promoted the increase of cellulose crystallinity. 


\section{ACKNOWLEDGEMENTS}

The authors acknowledge the following projects for financial support: National Technology Research and Development of China (863 Program) (No. 2007AA03Z433), Science and Technology Key Project of Guangdong Province, China (No. 2008A030202008), Science and Technology Plan Project of Guangdong Province, China (No. 2008B 030302035), and Major Program on Energy-Conservation and EmissionReducing of Guangdong province, China (No. 2008A080800003).

\section{REFERENCES CITED}

Aggerbrandt, L. G., and Samuelsson, O. (1964). "Penetration of water-soluble polymers into cellulose fibers," J. Appl. Polym. Sci. 8, 2801-2812.

Andreasson, B., Forsström, J., and Wågberg, L. (2003). "The porous structure of pulp fibers with different yields and its influence on paper strength," Cellulose 10, 111123.

Back, E. L., and Klinga, L. O. (1963). "The effect of heat treatment on internal stresses and permanent dimensional changes of paper," Tappi J. 46(5), 284-288.

Back, E. L., Htun, M. T., Jackson, M., and Johanson, F. (1967). "Ultrasonic measurements of the thermal softening of paper products and the influence of thermal auto-cross-linking reactions," Tappi J. 50(11), 542-547.

Bajpai, P. K. (2010). "Solving the problems of recycled fiber processing with enzymes," BioResources 5(2), 1-15.

Barrett, E. P., Joyner, L. G., and Halenda, P. P. (1951). "The determination of pore volume and area distributions in porous substances. I. Computations from nitrogen isotherms," J. Am. Chem. Soc. 73, 373-380.

Berthold, J., and Salmén L. (1997). "Inverse size exclusion chromatography (ISEC) for determining the relative pore size distribution of wood pulps," Holzforschung 51(4), 361-368.

Bežanović, D., Van Duijn, C. J., and Kaasschieter, E. F. (2007). “Analysis of wet pressing of paper: The three-phase model. Part I: constant air density," Transp. Porous Media 67, 93-113.

Blomstedt, M., Mitikka-Eklund, M., Vuorinen, T. (2007). "Simplified modification of bleached softwood pulp with carboxymethyl cellulose," Appita J. 60 (4), 309-314.

Böttger, J., Thi, L., and Krause, T. (1983). "Untersuchungen zur Porenstruktur von Zellstoffasern," Das Paper 37(10A), V14-V19.

Brancato, A., Walsh, F. L., Sabo, R., and Banerjee, S. (2007). "Effects of recycling on the properties of paper surfaces," Ind. Eng. Chem. Res. 46, 9103-9106.

Carlsson, G., and Lindström, T. (1984). "Hornification of cellulose fibers during wet pressing," Swensk Papperstidn. 87(15), R119-R125.

Chevalier-Billosta, V., Joseleau, J.-P., Cochaux, A., Ruel, K. (2007). "Tying together the ultrastructural modifications of wood fibre induced by pulping processes with the mechanical properties of paper," Cellulose 14, 141-152. 
China Paper Association. (2010). "The annual report of China's paper industry in 2009," China Pulp Pap. Ind. 31(11), 8-18.

Choi, Y. S., Jong, M. W. (2001). “Improvement of papermaking properties of recycled fiber with enzyme," Palpu Chongi Kisul 33(1), 30-37.

Ehrnrooth, E., Htun, M. and de Ruvo, A. (1978). Fiber-Water Interactions in Papermaking, in Trans. BPBIF Symp., London, 2, 899-915.

Emerton, H. W. (1957). Fundamentals of the Beating Process, Marshal Press, London, pp. 84-137.

Ekevåg, Lindström, T., Gellerstedt, G., and Lindström, M. (2004). "Addition of carboxymethylcellulose to the kraft cook," Nord. Pulp Pap. Res. J. 19(2), 200-207.

Forsström, J., Andreasson, B., and Wågberg, L. (2005). "Influence of pore structure and water retaining ability of fibers on the strength of papers from unbleached kraft fibers," Nord. Pulp Pap. Res. J. 20(2), 176-185.

Gregg, S. J., and Sing, K. S. W. (1982). Adsorption Surface Area and Porosity, 2nd Ed. Academic Press, London.

Gumuskaya, E., Usta, M., and Kirci, H. (2003). "The effects of various pulping conditions on crystalline structure of cellulose in cotton linters," Polym. Degrad. Stab. 81, 559-564.

Guo, W. J., Wang, Y., Wan, J. Q, Ma, Y. W. (2011). "Effects of slushing process on the pore structure and crystallinity in old corrugated container cellulose fibre," Carbohydr. Polym. 83, 1-7.

Häggkvist, M., Li, T. Q., and Ödberg, L. (1998). "Effects of drying and pressing on the pore structure in the cellulose fiber wall studied by $1 \mathrm{H}$ and $2 \mathrm{H}$ NMR relaxation," Cellulose 5, 33-49.

Hubbe, M. A., Venditti, R. A., Barbour, R. L., and Zhang, M. (2003). 'Changes to unbleached kraft fibers due to drying and recycling," Prog. Paper Recycling 12(3), 11-20.

Hubbe, M. A., Venditti, R. A., Rojas, O. J. (2007). "What happens to cellulosic fibers during papermaking and recycling? A review". Bioresources 2(4), 739-788.

Ingram, P., Woods, D. K., Peterlin, A. and Williams, J. L. (1974). "Never-dried cotton fibers, Part I: Morphology and Transport Properties," Text. Res. J. 44(2), 96-106.

Ioelovich, M. (2010). "Structure and properties nano-particles used in paper compositions," XXI TECNICELPA Conference and Exhibition / VI CIADICYP 2010 12-15 October 2010, Lisbon, Portugal)

Jayme, G. (1944). "Micro-swelling measurement in cellulosic pulp,” Papier-fabr. / Wochenbl. Papierfabr. 6, 187-194.

Jayme, G. and Hunger, G. in "Fundamentals of Papermaking Fibers", ed. by Bolman, F. BPBMA, Kenley, Eng., (1958).

Jiao, R., Peng, Y.X., Gao, P.J. (1998). "The study of improving the properties of recycled reed pulp," China Pulp Pap. Ind. (3), 39-41.

Laine, J., Lindström, Glad Nordmark, G., and Risinger, G. (2000). "Studies on topochemical modification of cellulosic fibers. Part 1. Chemical conditions for the attachment of carboxymethyl cellulose onto fibers," Nord. Pulp Pap. Res. J. 15(5), $520-526$. 
Laine, J., Lindström, Glad Nordmark, G., and Risinger, G. (2002). "Studies on topochemical modification of cellulosic fibers. Part 2. The effect of carboxymethyl cellulose attachment on fiber swelling," Nord. Pulp Pap. Res. J. 17(1), 50-56.

Laine, J., Lindström, Glad Nordmark, G., and Risinger, G. (2003). "Studies on topochemical modification of cellulosic fibers. Part 5. Comparison of the effects of surface and bulk chemical modification and beating on pulp and paper properties," Nord. Pulp Pap. Res. J. 18(3), 325-332.

Li, C. Y., Tang, Y. J., Wu, S., Xue, G. X. (2010). "Change of chemical compositions of recycled OCC pulp and the fiber damage characterization," Paper and Papermaking 29(7), 25-28.

Li, T. Q., and Eriksson, U. (1994). "Kaolin-based coating layer studied by $2 \mathrm{H}$ and $1 \mathrm{H}$ NMR relaxation method," Langmuir (10), 4624-4629.

Li, T. Q., Henriksson, U., and Ödberg, L. (1993). "Determination of pore sizes in wood cellulose fibers by $2 \mathrm{H}$ and $1 \mathrm{H}$ NMR," Nord. Pulp Pap. Res. J. 8(3), 326-330.

Lofton, M. C., Moore, S. M., Hubbe, M. A., and Lee, S. Y. (2005). "Polyelectrolyte complex deposition as a mechanism of paper dry-strength development," Tappi $J$. $4(9), 3-7$.

Lvov, Y. M., Grozdits, G. A., Eadula, S., Zheng, Z. G, and Lu, Z. H. (2006). "Layer nanocoating of mill broken fibers for improved paper," Nord. Pulp Pap. Res. J. 21(5), 552-557.

Lyne, L. M., and Gallay, W. (1950). "The effect of drying and heating on the swelling of cellulose fibers and paper strength," Tappi J. 33(9), 429-435.

Maloney, T. C., Li, T. Q., Weise, U., and Paulapuro, H. (1997). "Intra-and inter-fiber pore closure in wet pressing," Appita J. 50(4), 301-306.

Maloney, T.C., and Paulapuro, H. (1999). "The formation of pores in the cell wall," $J$. Pulp Pap. Sci. 25(12), 430-436.

Mancosky, D. G., Lucia, L. A., and Deng, Y. L. (2004). "The effects of lignocellullosic fiber surface area on the dynamics of lignin oxidation and diffusion," J. Appl. Polym. Sci. 94(1), 177-181.

Morosoff, N. (1974). "Never-dried cotton fibers. III. Crystallinity and crystallite size," J. Appl. Polym. Sci. 18, 1837-1854.

Nazhad, Mousa M. (1994). "Fundamentals of strength loss in recycled paper," Doctoral dissertation, The Univerity of British Columbia.

Nazhad, M. M., and Sodtivarakul, S. (2004). "OCC pulp fractionation - A comparative study of fractionated and unfractionated stock," Tappi J. 3(1), 35-50.

Nelson, M. L., and O' Connor, R. T. (1964). "Relation of certain infrared bands to cellulose crystallinity and crystal lattice type. Part II. A new infrared ratio for estimation of crystallinity in cellulose I and II," J. Appl. Polym. Sci. 8, 1325-1341.

Karnis, A. (1994). "The mechanism of fiber development in mechanical pulping," J. Pulp Pap. Sci. 20(10), 280-288.

Khantayanuwong, S. (2002a). "Effects of beating and recycling on strength of pulp fibers and paper," Kasetsart J. (Nat. Sci.) 36, 193-199.

Khantayanuwong, S., Enomae, T., Isogai, A., and Onabe, F. (2002b). "Changes in crystallinity and re-swelling capability of pulp fibers by recycling treatment," Japan Tappi J. 56(6), 863-869. 
Kongdee, A., Bechtold, T., Burtscher, E., Scheinecker, M. (2004). "The influence of wet/dry treatment on pore structure-the correlation of pore parameters, water retention and moisture regain values," Carbohydrate Polymers 57, 39-44.

Kulshreshtha, A. K., Patel, K. F., Patel, A. R., Patel, M. M., and Baddi, N. T. (1973). "The crystallinity of never-dried cotton," Cell. Chem. Tech. 7, 343-346.

Pala, H., Lemos, M.A., Mota, M., and Gama, F. M. (2001). "Enzymatic upgrade of old paperboard containers," Enzym. Microb. Technol. 29, 274-279.

Park, S., Venditti, R. A., Jameel, H., and Pawlak, J. J. (2006). "Changes in pore size distribution during the drying of cellulose fibers as measured by differential scanning calorimetry," Carbohydrate Polymers 66, 97-103.

Persson, P. V., Hafrén, J., Fogden, A., Daniel, G., and Iversen, T. (2004). "Silica nanocasts of wood fibers: A study of cell-wall accessibility and structure," Biomacromolecules 5, 1097-1101.

Rácz, I., and Borsa, J. (1997). "Swelling of carboxymethylated cellulose fibers," Cellulose 4, 293-303.

Robertson, A. A. (1964). "Some observations on the effects of drying papermaking fibers," Pulp Paper Mag. Can. 65(3), T161-T168.

Salmen, L. (1988). "Crystallinity effects on mechanical properties of H-bond-dominated solids," Comments on the recent article by Batten and Nissan. Tappi J. 70(12), 190193.

Sawabe, O., and Kitagawa, S. (1978). "Pore structure in swollen native cellulose: Association with structural feature of native cellulose," (in Japanese). Mokuzai Gakkaishi 24, 164-170.

Seo, Y. B., Yang, J., Yoon, C. S., and Kim, D. (2002). "Effect of mechanical impact treatment on fibre morphology and handsheet properties," Appita J. 55(6), 475-479.

Sheikhi, P., Talaeipour, M., Hemasi, A. M., Eslam, H. K., and Gumuskaya, E. (2010). "Effect of drying and chemical treatment on bagasse soda pulp properties during recycling," BioTesources 5(3), 1702-1716.

Stana-Kleinschek, K., Kreze, T., and Ribitsch, V. (2001). "Reactivity and electrokinetic properties of different types of regenerated cellulose fibres," Colloids Surf. A: Physicochem. Eng. Aspect, 195, 275-284.

Stone, J. E., and Scallan, A. M. (1965). "The effect of component removal upon the porous structure of the cell wall of wood," J. Polym. Sci. Part C- Polym. Symp. 11(1), $13-25$.

Stone, J. E., and Scallan, A. M. (1966). "Influence of drying on the pore structures of the cell wall," in Consolidation of the Paper Web, Trans. Symp. Cambridge, Sept. 1965, F. Bolam (ed.), Tech. Sec. British Paper and Board Makers' Assoc. Inc., London, Vol. 1, 145-174.

Stone, J. E., and Scallan, A. M. (1968). "A structural model for the cell wall of waterswollen wood pulp fibers based on their accessibility to macromolecules," Cell. Chem. Technol. 2(3), 343-358.

Thode, E. F., Chase, A. J., and Hu, Y. (1955). "Dye adsorption on wood pulp. IV. Note on effect of drying of pulp on specific dye adsorption," Tappi J. 38(2), 88-89.

Vainio, A. and Paulapuro, H. (2007). "The effect of wet pressing and drying on bonding and activation in paper," Nord. Pulp Pap. Res. J. 22(4), 403-408. 
Wang, X., Maloney, T. C., and Paulapuro, H. (2003). "Internal fibrillation in never-dried and once-dried chemical pulps," Appita J. 56(6), 455-459.

Wang, X., Maloney, T. C., and Paulapuro, H. (2006). "Improving the properties of neverdried chemical pulp by pressing before beating," Nord. Pulp Pap. Res. J. 21(1), 135139.

Waterhouse, J. F., and Liang, Y. X. (1995). "Improving the fines performance of recycled fiber pulps," In: Recycling Symposium Proceedings, TAPPI Press, pp. 103-116.

Wu, S., Tang, Y. J., Zhao, Y., and Xue, G. X. (2010). "Influence of recycling on OCC pulp strength and fiber surface properties," Transactions of China Pulp and Paper 25(13), 38-41.

Yu, C. T., Chen, W. H., Men, L.C., and Hwang, W. S. (2009). "Microscopic structure features changes of rice straw treated by boiled acid solution," Ind. Crops Prod. 29, 308-315.

Article submitted: November 2, 2010; Peer review completed: December 11, 2010; Revised version received and accepted: March 18, 2011; Published: March 21, 2011. 